\title{
Study of the Different Factors That Influence Jet Pump Performance
}

\author{
A. A. Saker, H. Z. Hassan \\ Public Authority of Applied Education and Training, Kuwait City, Kuwait \\ Email: alaa_saker@yahoo.com
}

Received March 14, 2013; revised April 15, 2013; accepted April 22, 2013

Copyright (C) 2013 A. A. Saker, H. Z. Hassan. This is an open access article distributed under the Creative Commons Attribution License, which permits unrestricted use, distribution, and reproduction in any medium, provided the original work is properly cited.

\begin{abstract}
The objective of this work is to study experimentally the characteristics of jet pump. Suction head, driving air pressure and the percentage of the distance between throat section and nozzle are recorded. The effect of each parameter on the pump performance is investigated, in order to have a better understanding about the behavior of such pump under various conditions. A simple geometry jet pump was designed, developed and tested. The experiments show that we should be careful in increasing the suction head, and stability must be considered between the suction head and the driving air mass flow rate. While the effect of increasing $\mathrm{P}_{\mathrm{a}}$ will stop at certain maximum of the ratio of the mass flow rate of water to air $(M)$, that is any increase in $P_{a}$ will meet no change in $M$. While increasing $S / D_{\text {th }}$ will leads to decrease in the percentage of $\mathrm{M}$ because the optimum $\mathrm{S} / \mathrm{D}_{\mathrm{th}}=0.5$ so that at this value we will have the best performance and any other values for $S / D_{\text {th }}$ the percentage $M$ will decreases, but this effect is not so clear and it could be neglected. The pump performance is not so sensitive with the change of $S / D_{\text {th }}$ after $S / D_{\text {th }}=0.5$. Also this information will help improving and extending the use of the jet pump in many practical applications.
\end{abstract}

Keywords: Jet Pump; Nozzle-Throat Interface; Driving Air Pressure

\section{Introduction}

The jet pump is a low-pressure high volume flow rate pump. Simplicity of design, absence of any moving parts, ability to handle muddy water, reliability, ruggedness, and low cost, more than compensate for the relatively poor efficiency of the pump. There has been little commercial interest in the development of low area jet pumps because of their characteristically low head rise. The basic components of jet pump are inlet nozzle, throat and diffuser.

Beside the later mentioned advantages of the jet pumps the applications through industry are too numerous to mention but some of the most common ones are, in power stations jet pump has been considered as an auxiliary boost pump in Rankine cycle, in ventilation and air conditioning, pneumatic or hydraulic conveyance of products in power form, coal and cinder transport in power plants, pumping of slug from shafts bore holes and pits, solid handling eductor is a special type called a hopper eductor, pumping sand from filter beds and sparkler nozzle which is the simplest type of eductors and steam lined eductors used to remove condensate from vessels under vacuum.
A model for jet pumps is driven under the assumption that the power and the well fluids are incompressible liquids several times. When either the well or the power fluid contains gas, Lisowski [1] used liquid water as motive and driven fluids. A flow phenomenon that appears during jet pump operation is investigated. Three designs of motive nozzle: standard, with additional circumferential holes and with set of circumferential holes are examined on motive nozzle. By modification of motive nozzle it is possible to increase pumping height with almost $45 \%$.

The same equations driven for incompressible liquids are used with modifying the mass flow rate ratio and the friction loss coefficient, in order to obtain an acceptable conformity between the theory and observation, we have to increase the hydraulic loss coefficient-up to 30 times for the present case study, which is closed-conduits, this level of correction has been determined by means of the trial and error method, Jerzy [2].

Zhu [3] studied the influence of different hydraulic structure on the efficiency, calculation results show that area ratio determines the suction capacity, throat length determines the mixing efficiency, and spray distance determines the outlet pressure. Most of the papers in the 
literature on the design of liquid-liquid jet pumps contain empirical information on the coefficient $S / D_{\text {th }}$. I. El-Sawaf [4] Study the effects of the pump operating conditions and geometries on the performance, the experimental investigations that the jet pump head and the head ratio decrease with increasing suction capacity and the area ratio $R\left(A_{n} / A_{M C}\right)$ of 0.25 gives the maximum highest efficiency and the area ratio of 0.155 gives a lowest efficiency. The optimum value for $S / \mathrm{D}_{\text {th }}$ for pumping water is about 1.0. Ibrahim [5] insure the same investigations and the driving pressure of 1 bar gives the maximum delivered concentration in case of $\mathrm{R}=0.25$ and 0.4 but at $\mathrm{R}=0.155$ the driving pressure of 1.5 bar gives the maximum delivered concentration.

In addition to promoting cavitation, interference between the nozzle exterior and the throat entry interior surfaces is an important cause of the large losses in the jet pumps. The distance between the driving nozzle to the beginning of mixing chamber to driving nozzle diameter ratio of 1.5 , gives the maximum for all tested cases. The mixing chamber length of 7.25 Dmix had proven superiority over the other two mixing chambers length of 6.75 and 7.86 Dmix. Mixing throat length ranging from 3.5 to approximately 10 times the throat diameters has been studied. Mueller [6] was one of the few investigators who measured the throat entry loss coefficient and his results graphically illustrate the profound effect of an adequate nozzle to throat spacing on the loss coefficient $\mathrm{K}_{\mathrm{en}}$ (If $\mathrm{S} / \mathrm{D}_{\mathrm{th}}=0.55$ where the measured $\mathrm{K}_{\mathrm{en}}$ value was $0.061)$. When the nozzle is inserted to $S / D_{\text {th }}=0.023$, the measured $\mathrm{K}_{\mathrm{en}}$ values were increased by an order of magnitude to 0.745 , actually this radical increase in the throat entry loss coefficient reflects a combination of the main flow losses and a secondary flow losses.

Vogal [7] measured the static pressure rise in a very long throat length up to 20 diameters in length, the results illuminated an often over looked point that is the dependence of optimum throat length on the flow ratio $\mathrm{M}$, regardless, of the design area ratio of the pump. For an area ratio of $\mathrm{R}=0.219$ he found that the pressure rise in the mixing throat is at 5.3 diameters at low secondary flows approaching the cut-off point, and the required or optimum mixing length increased many times the diameters at high values of the flow ratio $\mathrm{m}$, i.e., under low $\mathrm{P}_{\mathrm{d}}$ conditions.

Schulz [8] used a larger area of area ratio $\mathrm{R}=0.219$ found that the pressure peaked at $\mathrm{L} / \mathrm{D}_{\text {th }}=4.2$ for $(\mathrm{M})$ goes to zero as contracted with a required mixing length of $\mathrm{L} / \mathrm{D}_{\text {th }}>8.3$ at a maximum flow ratio.

The mixing length required to achieve maximum pressure rise in the throat is properly viewed as the total distance from the tip of the nozzle to completion of mixing. i.e. $\left(\mathrm{S} / \mathrm{D}_{\mathrm{th}}+\mathrm{L} / \mathrm{D}_{\mathrm{th}}\right)$. Note that the optimum $\mathrm{S} / \mathrm{D}_{\text {th }}$ increased from zero for the longest throat to 2.3 throat di- ameters for the shortest length. Since the $L / D_{\text {th }}$ values declined at a more rapid rate than growth in $S / D_{\text {th }}$, the totals declined somewhat. Note that the peak efficiency was obtained with the intermediate case, i.e., 1 diameter spacing and a 5.66 diameter mixing throat length show in the same table for two short-throat pumps.

The same trend is evident; namely, a reduction in throat length requires a doubling in nozzle to throat spacing. Sanger's [9] study provided further information on one of the undesirable effects of excessive S/Dth values when used with a long (7.25)-mixing throat. The corresponding static pressure profiles with $\mathrm{S} / \mathrm{D}_{\text {th }}=0$ or 0.96 showed continuous pressure rise through the throat and leveling off at the exit, indicating an optimum length. In contrast, a similar profile with $\mathrm{S} / \mathrm{D}_{\text {th }}=2.68$ resulted in a throat pressure rise, which peaked at about 4.5 diameters and then declined due to frictional losses in the throat.

Unfortunately, the liquid jet pump is increasingly prone to cavitation as the throat spacing $\left(S / D_{\text {th }}\right)$ is reduced to zero. Static pressure measurements at the throat entry show that zero spacing causes large pressure drops at the throat entry and consequently promotes cavitation. For $\mathrm{S} / \mathrm{D}_{\text {th }}=0$ optimum nozzle setting for pump efficiency.

Hammoud [10] showed that nozzle to throat spacing to nozzle diameter ratio (L/D), for optimum jet pump performance the drive pressure was of 1.5 bar, while increasing the motive pump pressure the pump performance decreased. Kumaraswamy [11] insured that nozzle to mixing tube spacing play an important role in the performance of the jet pump.

\section{Expermental Set-Up and Measurement}

The test rig description and components are herein introduced to demonstrate its ability to determine the value performance and to study the different parameters affecting this value. Consequently, the operational concept, detailed design of the jet pump and its internal components are illustrated. Subsequently, the measurement techniques and uncertainty analysis are introduced. Finally test rig tuning up is achieved. The experimental apparatus of steam jet pump is shown in Figure 1. It consists of compressed air tank, feed water tank, delivered water tank, manometer, orifice meter, jet pump, and other associated equipment's for flow control and measurement.

A 500 liter pressurized air tank is connected to a secondary 150-liter tank to increase the pressure feeding stability. The secondary tank is connected by a control valve to the orifice meter designed according to the BRITCH STANDERED (BS-1042 Part-1 1964). The orifice meter is connected to the nozzle-tube by a galvanized $18 \mathrm{~mm}$ pipe. A pressure gauge is inserted just before the nozzle-tube to measure the driving air pressure. 


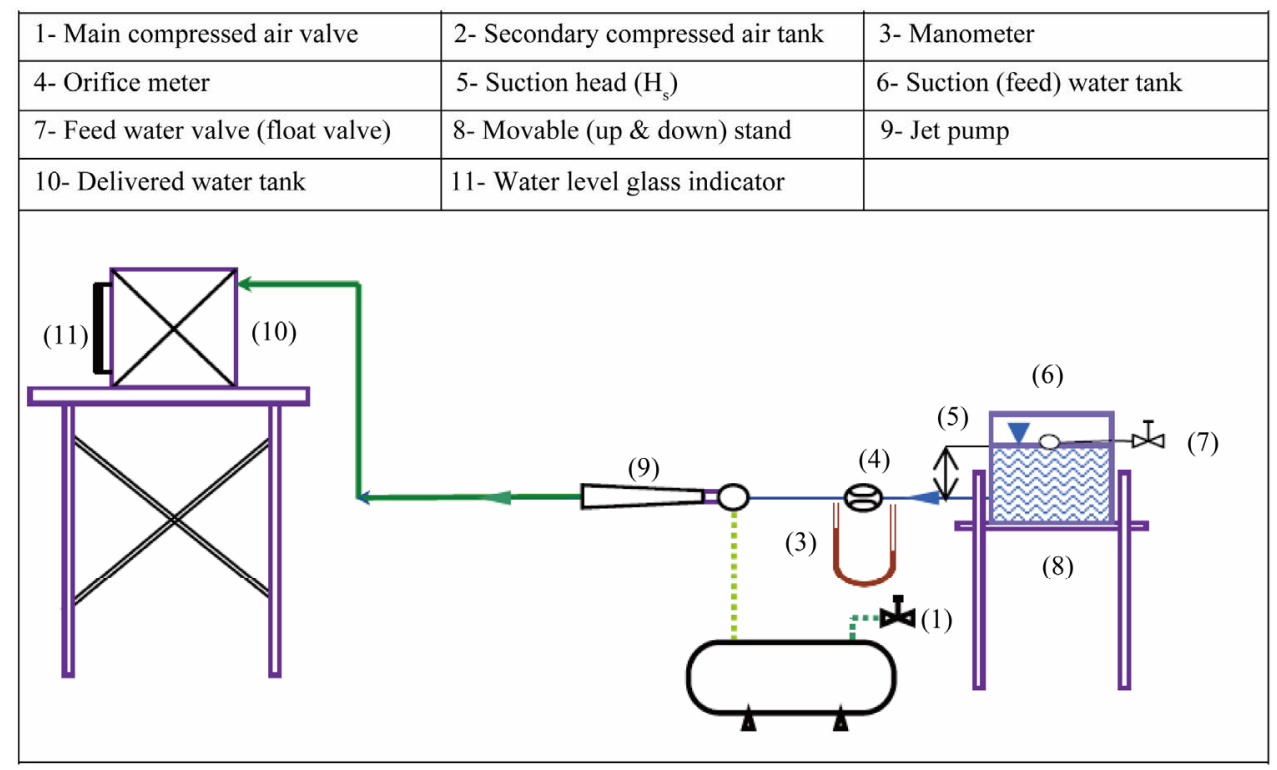

Figure 1. Schematic diagram of the set-up assembly.

The Jet Pump consists of a converging diverging tube fabricated from Perspex plastic for visual observations studies, see Figure 2.

The upstream air pressure is measured using Bourdon gauge with measuring range of $0-10$ bar with $\pm 2 \%$ accuracy of full scale, while downstream air pressure is measured using Digital compound gauge with measuring range of 0 - 10 bar with $\pm 0.1 \%$ accuracy of full scale. water mass flow rate is measured using graduated cylinder and stop watch. Air mass flow rate is measured using an orifice meter, of discharge coefficient $\left(\mathrm{C}_{\mathrm{d}}\right) 62.5 \%$, with measuring range $0-500 \mathrm{~mm}$ and $\pm 2 \mathrm{~mm}$ accuracy as shown in Figure 3.

\section{Results and Discussion}

In this work the jet pump is studied experimentally to investigate the effect of Suction head, driving air pressure and the percentage of the distance between throat section and nozzle on the pump performance. Such parameters are studied and discussed below.

Figures 4(a)-(c) shows the relation between the driving air mass flow rate, and water mass flow rate at a constant $\mathrm{S} / \mathrm{D}_{\text {th }}=0.5,1.5$, and 3.0, respectively for different suction heads $\left(\mathrm{H}_{\mathrm{s}}=-10,10,20,30 \mathrm{~cm}\right)$. The driving air momentum starts to entrain water at flow rate of $1.1 \times$ $10^{-2} \mathrm{Kg} / \mathrm{sec}$ (corresponding to a supply pressure of approximately $6.5 \mathrm{~atm}$.). The results show that $\mathrm{mw}$ is directly proportional to ma at various values of both $\mathrm{H}_{\mathrm{s}}$ and $\mathrm{S} / \mathrm{D}_{\text {th }}$. Also, increasing the suction head improves the pump performance, where the water mass flow rate increases at the same driving air flow rate. Besides, decreasing $S / D_{\text {th }}$ causes a slight increase in the water mass flow rate.
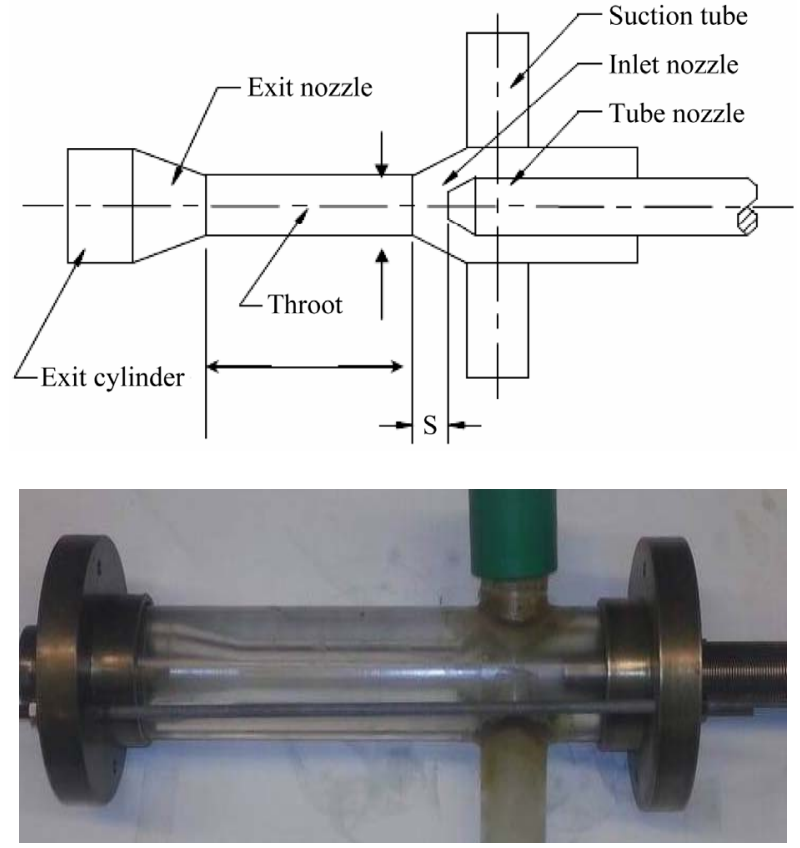

Figure 2. Schematic diagram of Jet pump components.

Figures 5(a)-(c) shows the variations of water to air mass ratio, against the driving pressure at $\mathrm{S} / \mathrm{D}_{\text {th }}=0.5,1.5$ and 3.0 respectively for different suction heads $\left(\mathrm{H}_{\mathrm{s}}=10\right.$, $20,30 \mathrm{~cm})$. The results reveal that increasing the driving pressure increases the driving air momentum that responsible for water entrainment mechanism through the pump. The geometrical parameter $S / D_{\text {th }}$ has a vital effect on the performance of the jet pump, where as it decreases the water to air mass ratio increased at constant driving pressure. Also, increasing suction head improves the entrained water. At certain value of the driving pressure, the 

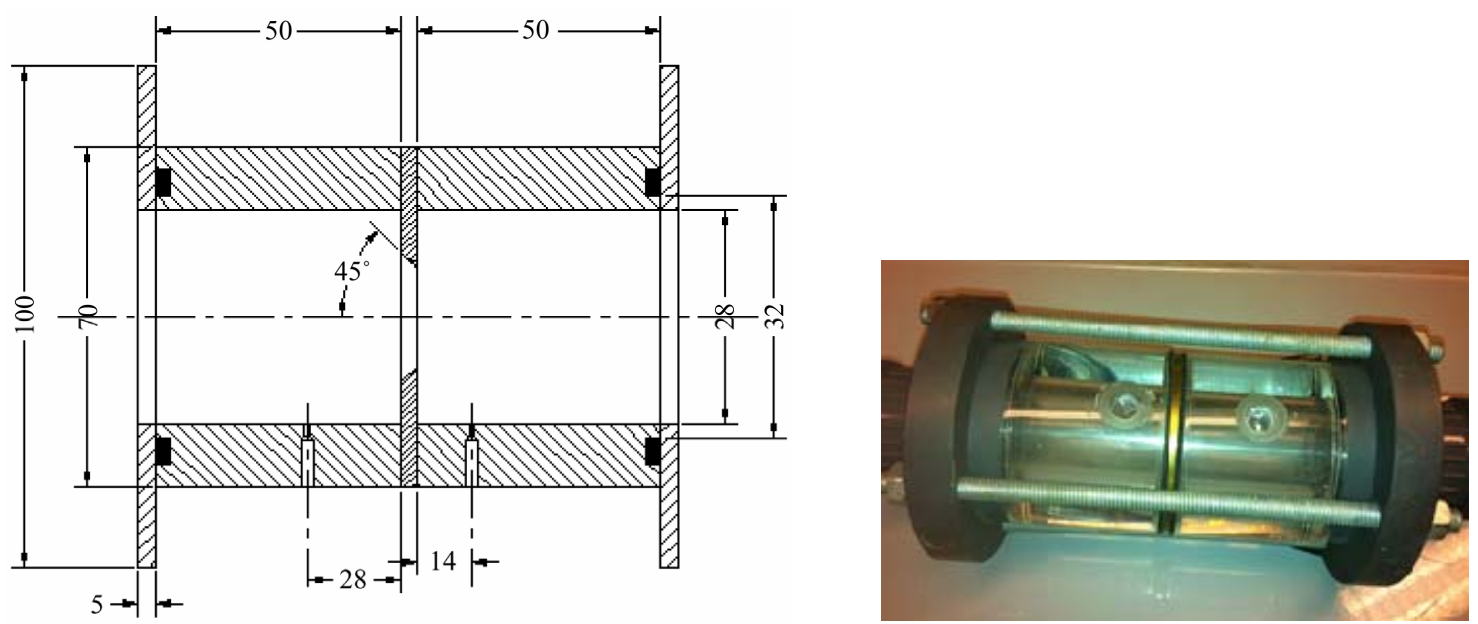

Figure 3. Schematic drawing and photo of the orifice meter assembly.

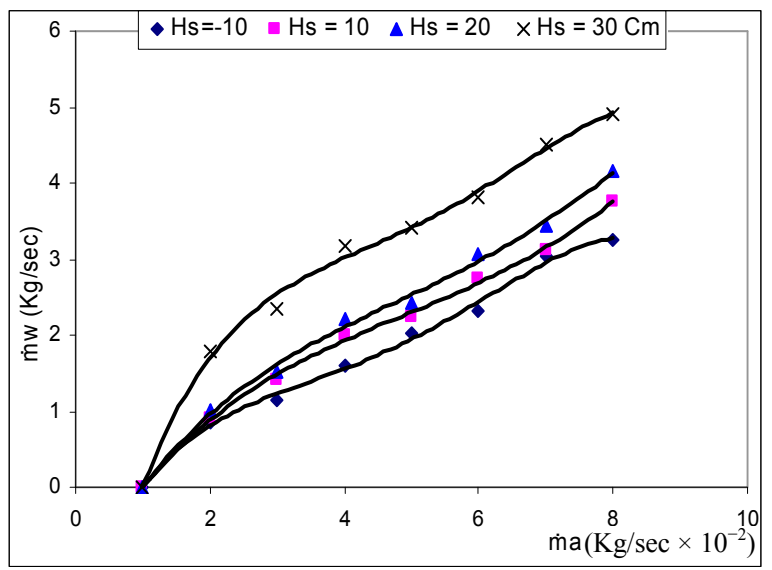

(a)

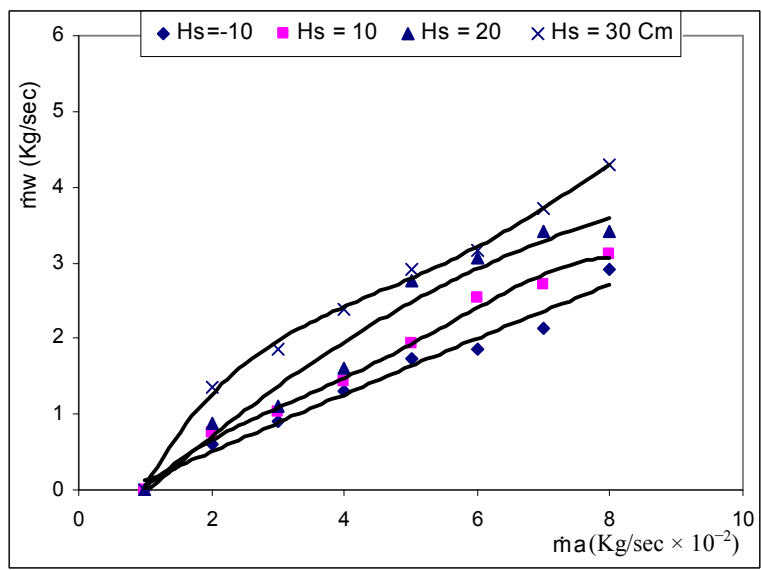

(b)

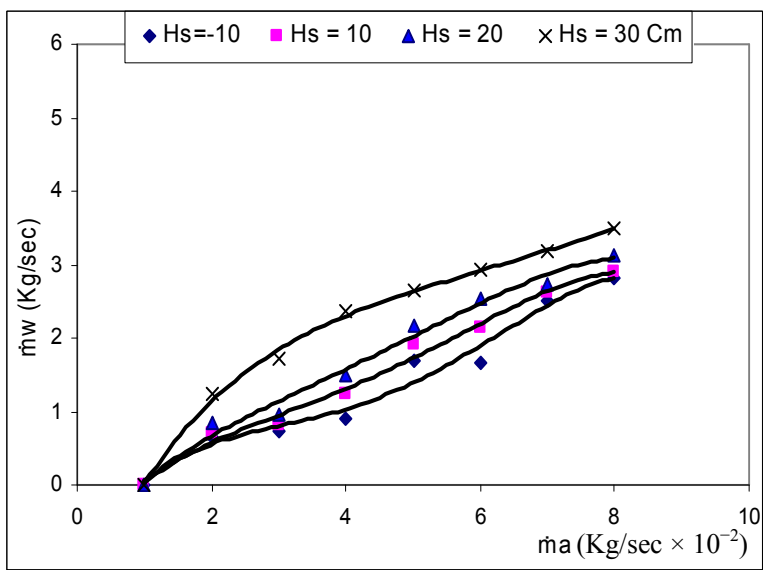

(c)

Figure 4. (a), (b), and (c) Relation between water mass flow rate and driving air mass flow rate at $\mathrm{S} / \mathrm{D}=0.5$, 1.5, and 3.0, respectively for different values of suction heads.

driving air is increased dramatically and consequently the water to mass ratio starts to decreases as shown from Figure 5.

Figures 6(a)-(c) shows the variations of water to air mass ratio, against the driving pressure at $\mathrm{H}_{\mathrm{s}}=10,20$, and $30 \mathrm{~cm}$, respectively for different values of $\left(\mathrm{S} / \mathrm{D}_{\mathrm{th}}=\right.$ $0.5,1.5$, and 3.0). The results depict that, increasing the driving pressure is the more power consumed to entrain 


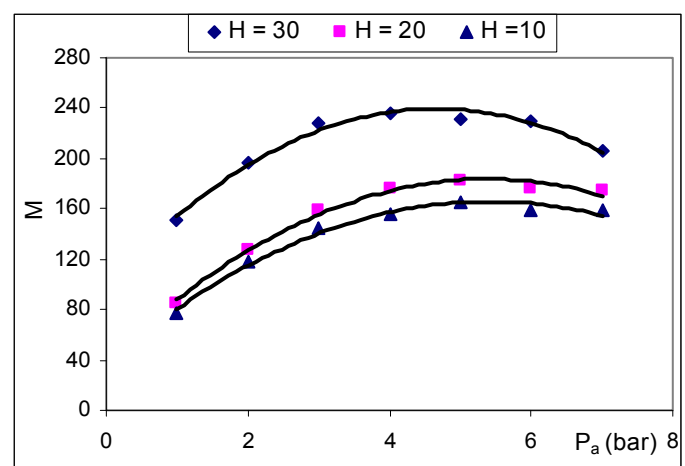

(a)

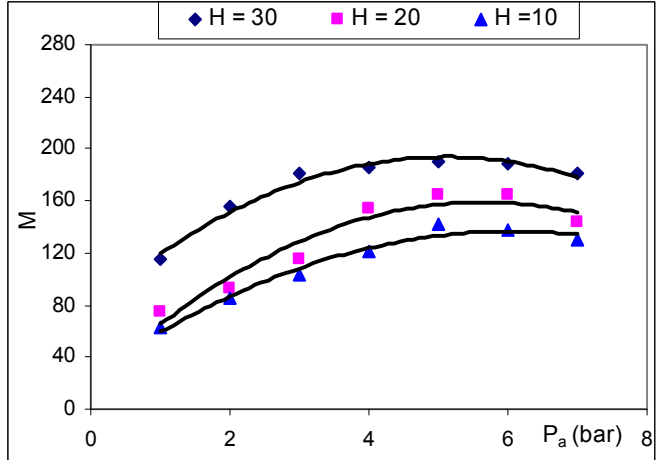

(b)

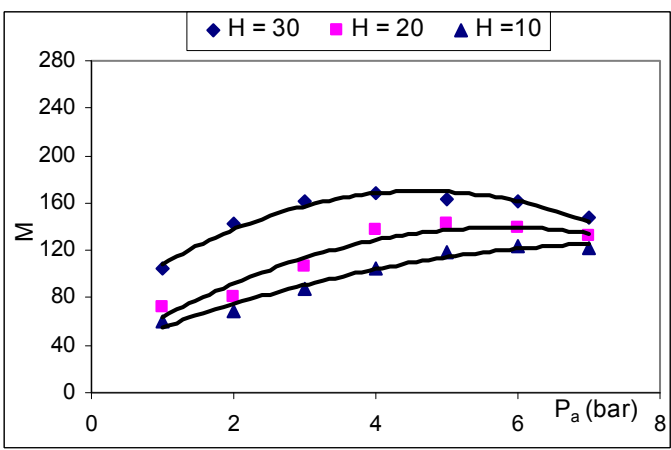

(c)

Figure 5. (a), (b), and (c) Relation between water to air mass ratio, and driving air pressure at $\mathrm{S} / \mathrm{D}=\mathbf{0 . 5}$, 1.5, and 3.0, respectively for different values of suction heads.

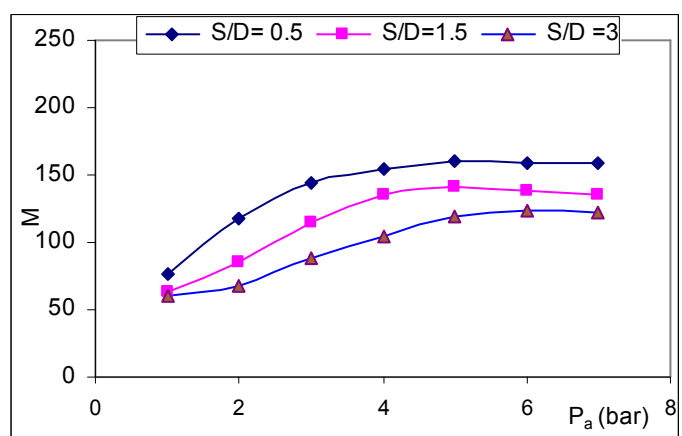

(a)

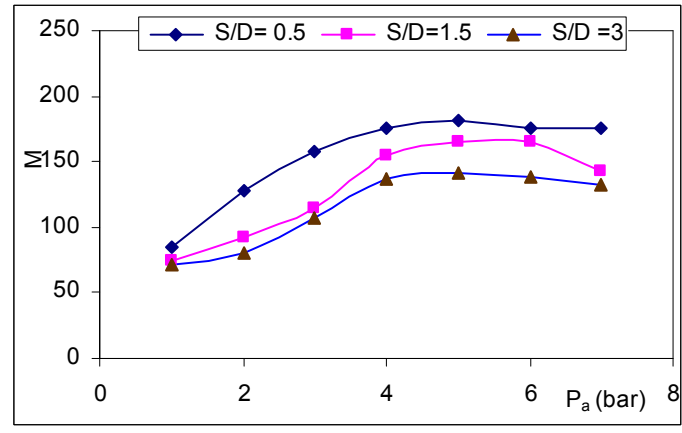

(b)

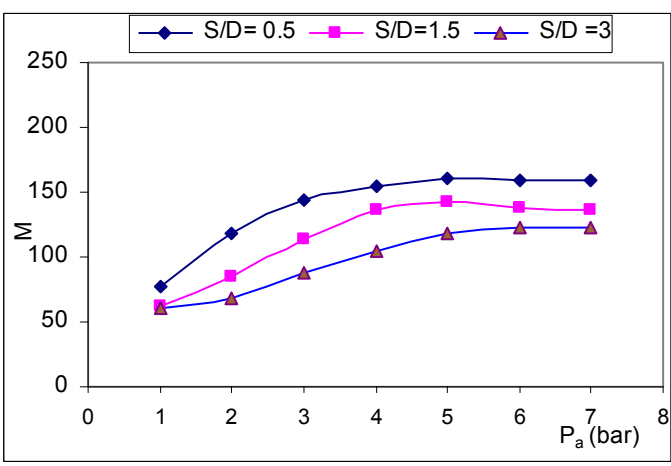

(c)

Figure 6. (a), (b), and (c) Relation between water to air mass ratio, and the driving air pressure at $\mathbf{H}_{\mathrm{s}}=10,20$, and $30 \mathrm{~cm}$, respectively for different values of $(\mathrm{S} / \mathrm{D})$. 
the water, and consequently additional cost of the pumping process. Hence, increasing the suction head and decreasing the geometrical parameter $\left(\mathrm{S} / \mathrm{D}_{\text {th }}\right)$ will recover the performance of the jet pump at the same driving pressure. Consequently, no additional cost is required anymore and the efficiency is conserved.

\section{Conclusions}

Increasing $\mathrm{H}_{\mathrm{s}}$ leads to increase in $\dot{\mathrm{m}}_{\mathrm{w}}$ for the same $\dot{\mathrm{m}}_{\mathrm{a}}$.

But the optimum performance is at $\mathrm{S} / \mathrm{D}_{\text {th }}=0.5$

The driving air pressure $\mathrm{P}_{\mathrm{a}}$ leads to proportional increase in $\mathrm{M}$ up to the optimum region, and then increasing $\mathrm{P}_{\mathrm{a}}$ will lead to decreases in $\mathrm{M}$. This means that driving air pressure must be limited otherwise it causes a reverse effect.

\section{REFERENCES}

[1] E. Lisowski and H. Momeni, "CFD Modeling of a Jet Pump with Circumferential Nozzles for Large Flow Rates," Archives of Foundry Engineering, Vol. 10, No. 3, 2010. pp. 69-72.

[2] J. M. Sawicki, "Hydraulic Loss Coefficient in 1D Flows," Archives of Hydro-Engineering and Environmental Mechanics, Vol. 54, No. 2, 2007, pp. 95-116

[3] H. J. Zhu, B. S. Qiu, Q. K. Jia and X. L. Yang, "Simulation Analysis of Hydraulic Jet Pump," Advanced Material

\section{Nomenclature}

A: Cross sectional area $\left(\mathrm{m}^{2}\right)$

$A_{t}$ : Total flow area $\left(\mathrm{m}^{2}\right)$

An: Nozzle (jet) cross sectional area $\left(\mathrm{m}^{2}\right)$

$\mathrm{A}_{\mathrm{MC}}$ : Mixing chamber cross sectional area $\left(\mathrm{m}^{2}\right)$

$\mathrm{C}_{\mathrm{d}}$ : Calibration coefficient from the orifice calibration curve $(-)$

$\mathrm{d}_{\mathrm{o}}$ : Orifice diameter $\left(\mathrm{m}^{2}\right)$

$\mathrm{D}_{\text {th }}$ : Driving nozzle exit diameter $\left(\mathrm{m}^{2}\right)$

D: Tube diameter $\left(\mathrm{m}^{2}\right)$

$\mathrm{D}_{\mathrm{oi}}$ : Orifice inside diameter $(\mathrm{m})$

$\mathrm{D}_{\mathrm{oo}}$ : Orifice outside diameter $(\mathrm{m})$

$\mathrm{D}_{\text {mix }}$ : Mixing chamber diameter $(\mathrm{m})$

$\mathrm{H}$ : Static suction head (m)

$\mathrm{H}_{\mathrm{s}}$ : Suction head is the net vertical distance between the water level in the feeding water tank and the center line of the suction tubes $(\mathrm{m})$

$\mathrm{K}$ : Constant (-)

$\mathrm{K}_{\mathrm{en}}$ : Friction loss coefficient, throat entrance (-)
Research, Vol. 204-210, 2011, pp. 293-296.

[4] I. A. El-Sawaf, M. A. Halawa, M. A. Younes and I. R. Teaima, "Study of the Different Parameters that Influence on the Performance of Water Jet Pump," Fifteenth International Water Technology Conference, Alexandria, 2011.

[5] R. T. Ibrahim, “A Central-Type Jet Pump Model For Wheat Grains Removing From Water Channels," Sixteenth International Water Technology Conference, Turkey, 2012.

[6] N. H. G. Mueller, "Water Jet Pump," 1964.

[7] R. Vogal, "Theoretische und Experimentelle Untersuchungen as Strohlopparaten," Vol. 5, Maschinenbautechnick, Berlin, 1965.

[8] F. Schulz and K. H. Fasol, "Wasserstahlpumen Zur Forderung Von Flussegkeiten," "Springer-Verlag, Vienna, 1958.

[9] N. L. Sanger, "Non-Cavitation Performance of Two Low Area Ratio Water Jet Pumps Having Throat Lengths of 7.25 Diameters," 1985.

[10] A. H. Hammoud, "Effect of Design and Operational parameters on Jet Pump Performance," Proceedings of the 4th WSEAS International Conference on Fluid Mechanics and Aerodynamics, Elounda, 21-23 August 2006, pp. 245252.

[11] V. P. sharma, S. Kumaraswamy and A. Mani, "Expermental Investigations with Nozzle in a Two Phase Flow Jet Pump," 2011.

$\mathrm{L}_{\mathrm{th}}$ : Throat length (m)

$\left(\dot{\mathrm{m}}_{\mathrm{a}}\right)$ : Air mass flow rate $\left(\mathrm{m}^{3} / \mathrm{s}\right)$

$\left(\dot{\mathrm{m}}_{\mathrm{w}}\right)$ : Water mass flow rate $\left(\mathrm{m}^{3} / \mathrm{s}\right)$

M: Water to air mass ratio $\left(\dot{\mathrm{m}}_{\mathrm{w}} / \dot{\mathrm{m}}_{\mathrm{a}}\right)(-)$

$\mathrm{N}$ : Efficiency \%

$\mathrm{P}_{\mathrm{a}}$ : The driving air pressure "pressure of the jet of air coming from the nozzle $(\mathrm{Pa})$

$\mathrm{P}_{\mathrm{US}}$ : Up-stream pressure $(\mathrm{Pa})$

$\mathrm{P}_{\mathrm{ds}}$ : Down-stream pressure $(\mathrm{Pa})$

$\mathrm{P}_{\mathrm{v}}$ : Vapor pressure $(\mathrm{Pa})$

R: Area ratio $\left(\mathrm{A}_{\mathrm{n}} / \mathrm{A}_{\mathrm{MC}}\right)(-)$

$\mathrm{S}$ : The distance between throat interface and driving nozzle interface $(\mathrm{m})$

$\mathrm{T}$ : Time $(\mathrm{Sec})$

$\mathrm{T}$ : Temperature $\left({ }^{\circ} \mathrm{C}\right)$

Z: High of water in the upper tank (Connected to the discharge line) $(\mathrm{m})$

A: Divergent or convergent angle $\left(^{\circ}\right)$ 